\title{
Resistance to anti-VEGF therapy in neovascular age-related macular degeneration: a comprehensive review
}

This article was published in the following Dove Press journal:

Drug Design, Development and Therapy

2 June 2016

Number of times this article has been viewed

\author{
Shiqi Yang' \\ Jingke Zhao' \\ Xiaodong Sun ${ }^{1-3}$ \\ 'Department of Ophthalmology, \\ Shanghai General Hospital, Shanghai \\ Jiao Tong University School of \\ Medicine, ${ }^{2}$ Eye Research Institute \\ of Shanghai Jiao Tong University, \\ ${ }^{3}$ Shanghai Key Laboratory of Fundus \\ Disease, Shanghai, People's Republic \\ of China
}

Correspondence: Xiaodong Sun Department of Ophthalmology, Shanghai General Hospital, Shanghai Jiao Tong University School of Medicine, 100 Haining Road, Shanghai 200080, People's Republic of China Tel/fax +86 21 $63240090 \times 6822$ Email xdsun@sjtu.edu.cn

\begin{abstract}
As a progressive chronic disease, age-related macular degeneration (AMD) is the leading cause of irreversible vision impairment worldwide. Experimental and clinical evidence has demonstrated that vascular endothelial growth factor (VEGF) plays a vital role in the formation of choroidal neovascularization. Intravitreal injections of anti-VEGF agents have been recommended as a first-line treatment for neovascular AMD. However, persistent fluid or recurrent exudation still occurs despite standardized anti-VEGF therapy. Patients suffering from refractory or recurrent neovascular AMD may develop mechanisms of resistance to anti-VEGF therapy, which results in a diminished therapeutic effect. Until now, there has been no consensus on the definitions of refractory neovascular AMD and recurrent neovascular AMD. This article aims at clarifying these concepts to evaluate the efficacy of switching drugs, which contributes to making clinical decision more scientifically. Furthermore, insight into the causes of resistance to anti-VEGF therapy would be helpful for developing possible therapeutic approaches, such as combination therapy and multi-target treatment that can overcome this resistance.
\end{abstract}

Keywords: age-related macular degeneration, vascular endothelial growth factor, choroidal neovascularization, resistance

\section{Introduction}

Age-related macular degeneration (AMD) is a progressive chronic disease. The World Health Organization has indicated that AMD ranks as one of the leading causes of blindness globally due to the aging populations in many countries. ${ }^{1}$ Neovascular AMD is characterized by pathologic choroidal neovascularization (CNV) that breaks through Bruch's membrane into the subretinal pigment epithelium space and/or the subretinal space, leading to exudation, hemorrhage, retinal edema, pigment epithelial detachment, and fibrous scarring, ${ }^{2}$ which may produce serious impairments in visual acuity.

$\mathrm{CNV}$ is a process that involves both angiogenesis and inflammation. ${ }^{3}$ Experimental and clinical evidence has shown that vascular endothelial growth factor (VEGF) is a key component in promoting neovascularization. ${ }^{4-6}$ Intravitreal anti-VEGF agents have greatly improved visual outcomes. ${ }^{7-13}$

There are five anti-VEGF agents approved for the treatment of neovascular AMD. Pegaptanib became the first one to be approved by the US Food and Drug Administration (FDA), which selectively binds VEGF $_{165^{\circ}}{ }^{14-16}$ The VISION study demonstrated that pegaptanib $0.3 \mathrm{mg}$ given intravitreally every 6 weeks resulted in $70 \%$ of patients losing fewer than 15 letters of visual acuity. ${ }^{8}$ However, pegaptanib has been gradually 
Table I Comparison of current anti-VEGF agents for neovascular AMD

\begin{tabular}{|c|c|c|c|c|c|}
\hline $\begin{array}{l}\text { Anti-VEGF } \\
\text { agents }\end{array}$ & Structure & Biological target & $\begin{array}{l}K_{\mathrm{D}} \text { for } \\
\text { VEGF }_{165}(\mathrm{pM})\end{array}$ & $\begin{array}{l}\text { Molecular } \\
\text { weight (kDa) }\end{array}$ & Approvals \\
\hline Pegaptanib & Pegylated RNA aptamer & VEGF-A ${ }_{165}$ only ${ }^{15}$ & $50^{14}$ & $50^{16}$ & FDA (2004) EMA (2005) \\
\hline Bevacizumab & $\begin{array}{l}\text { Recombinant humanized monoclonal } \\
\operatorname{lgGI} \text { antibody }\end{array}$ & All isoforms of VEGF-A ${ }^{18}$ & $58^{19}$ & $149^{19}$ & $\begin{array}{l}\text { FDA (2004) EMA (2005) } \\
\text { CFDA (2010) }\end{array}$ \\
\hline Ranibizumab & $\begin{array}{l}\text { Recombinant humanized } \lg G \mathrm{I}-\kappa \\
\text { isotype monoclonal antibody fragment }\end{array}$ & All isoforms of VEGF-A ${ }^{17}$ & $46^{19}$ & $48^{17}$ & $\begin{array}{l}\text { FDA (2006) EMA (2007) } \\
\text { CFDA (2012) }\end{array}$ \\
\hline Aflibercept & $\begin{array}{l}\text { Fusion protein: domain } 2 \text { of VEGFR-I } \\
\text { and domain } 3 \text { of VEGFR-2 fused with } \\
\text { IgGI Fc }\end{array}$ & $\begin{array}{l}\text { All isoforms of VEGF-A, } \\
\text { VEGF-B, and PIGF }{ }^{23}\end{array}$ & $0.5^{23}$ & $115^{19}$ & $\begin{array}{l}\text { FDA }(2011) \\
\text { EMA }(2012)\end{array}$ \\
\hline Conbercept & $\begin{array}{l}\text { Fusion protein: domain } 2 \text { of VEGFR-I } \\
\text { and domains } 3 \text { and } 4 \text { of VEGFR-2 } \\
\text { fused with } \operatorname{lgGI} \mathrm{Fc}\end{array}$ & $\begin{array}{l}\text { All isoforms of VEGF-A, } \\
\text { VEGF-B, VEGF-C, and PIGF } 25\end{array}$ & $0.5^{24}$ & $143^{24}$ & CFDA (20I3) \\
\hline
\end{tabular}

Abbreviations: AMD, age-related macular degeneration; CFDA, China Food and Drug Administration; EMA, European medicines agency; FDA, US Food and Drug Administration; IgG, immunoglobulin $G$; $\mathrm{K}_{\mathrm{D}}$, binding affinity to VEGF-A $\mathrm{A}_{165}$; PIGF, placental growth factor; RNA, ribonucleic acid; VEGF, vascular endothelial growth factor; VEGFR, vascular endothelial growth factor receptor.

replaced by the pan-VEGF-A inhibitors. Ranibizumab is a humanized monoclonal Fab fragment, while bevacizumab is a full-length humanized monoclonal antibody. These drugs could neutralize all the active isoforms of VEGFA. ${ }^{17-19}$ Ranibizumab was demonstrated to be effective in the MARINA and ANCHOR trials, based on the observation that $\sim 90 \%$ of patients receiving monthly intravitreal treatment with ranibizumab lost fewer than 15 letters after 2 years. ${ }^{7,10}$ Bevacizumab presented a similar efficacy to ranibizumab in the CATT trials and IVAN study. ${ }^{9,11,20}$ Aflibercept and conbercept are recombinant fusion proteins that act as soluble decoy receptors for VEGF family members. ${ }^{21-25}$ In the Phase III VIEW 1 and 2 trials, the administration of an intravitreal aflibercept injection monthly or every 2 months after three initial monthly doses achieved similar visual outcomes comparable to monthly intravitreal ranibizumab. ${ }^{12}$ Conbercept was tested in the AURORA study, and most patients reported improved functional and morphologic parameters. ${ }^{13}$ A comparison of current anti-VEGF agents for neovascular AMD is shown in Table 1. As the incidence of severe vision loss and blindness has been greatly reduced by $46 \%-51 \%$ in many countries, ${ }^{26-28}$ anti-VEGF therapy is now considered a first-line treatment for neovascular AMD.

Although anti-VEGF agents have shown a dramatic breakthrough in neovascular AMD treatment recently, some patients have poor or nonresponse to anti-VEGF agents with standardized treatment or experience a slow loss of efficacy of anti-VEGF agents after repeated administration over time. Persistent fluid is still common after regular therapy. The CATT revealed that, despite monthly treatment with anti-VEGF agents for 2 years, $51.5 \%$ of patients receiving intravitreal ranibizumab and $67.4 \%$ of patients treated with bevacizumab had evidence of persistent fluid on time-domain optical coherence tomography (OCT). ${ }^{11}$ There are still $19.7 \%-36.6 \%$ of patients with active exudation on either angiography or OCT after 1 year of regular $2.0 \mathrm{mg}$ aflibercept treatments (q4wk or q8wk). ${ }^{12}$

For these phenomena, researchers have offered various descriptions and explanations about the loss of the drug's effectiveness, such as "incomplete response", ${ }^{29}$ "poor response", ${ }^{30}$ "nonresponse",30,31 "unresponsive", ,32 "tolerance",,33-35 "tachyphylaxis", ,4-40 "treatment resistant", 41-43 "resistance to anti-VEGF", 44 "refractory to anti-VEGF", ${ }^{45}$ and "resistance to anti-VEGF treatment". ${ }^{46}$ When describing and classifying patients with persistent fluid or recurrent exudation, researchers frequently use the terms "refractory neovascular AMD", 47-50 "recalcitrant neovascular AMD", 51-54 "recurrent neovascular AMD", ${ }^{44,47,55-57}$ and "treatment-resistant neovascular AMD". ${ }^{41-43}$ However, no present agreement exists on the definition of these terms, and this point has been highlighted and marked as needing further action. Clarifying and consolidating these concepts are of great importance for an effective evaluation of switching to other anti-VEGF drugs, combination therapy, and multi-target treatment. Furthermore, gaining an insight into the causes of resistance to anti-VEGF therapy would be helpful for developing novel strategies to improve the efficacy of antiangiogenic therapies.

\section{Definition of refractory neovascular AMD and recurrent neovascular AMD Refractory neovascular AMD}

In many clinical trials and scientific papers, researchers frequently use the terms "refractory neovascular AMD" and "recalcitrant neovascular AMD", but there is still debate 
regarding what can be defined as "refractory neovascular AMD" or "recalcitrant neovascular AMD". Some researchers consider patients who show stationary or increased intraretinal or subretinal exudation despite more than three consecutive injections, even if an initial partial response could be observed temporarily, to be suffering from refractory neovascular AMD or recalcitrant neovascular AMD. ${ }^{45,47,48,58,59}$ Arcinue et $\mathrm{al}^{44}$ concluded that eyes with persistent fluid collection despite at least five monthly consecutive ranibizumab/bevacizumab injections might qualify as refractory neovascular AMD as well.

Previously, many researchers considered that patients with persistent fluid after three initial injections suffer from refractory or recalcitrant AMD, which is mainly based on remarkable vision improvement after three monthly injections. However, as the responses of $>30 \%$ of patients were delayed after 4 months of treatment in the MARINA and ANCHOR trials, ${ }^{7,10}$ a response to only three initial injections should not be considered an indicator of visual prognosis. Therefore, some researchers considered to redefine the threshold for refractory or recalcitrant AMD. Broadhead et $\mathrm{al}^{41}$ considered persistent exudation after at least 6-month regular anti-VEGF therapy, which could be defined as "treatment resistance". Fung et $\mathrm{al}^{55}$ defined "refractory CNV" as persistent fluid on spectral-domain OCT (SD-OCT) at $<30$ days after the last of six intravitreal injections of an anti-VEGF agent at monthly intervals. Grewal et $\mathrm{al}^{52}$ put forward the concept of "recalcitrant exudative AMD" after 6 months of monthly anti-VEGF treatment.

Since "recalcitrant neovascular AMD" and "refractory neovascular AMD" are synonyms, we recommend the uniform use of "refractory neovascular AMD". We consider that "refractory neovascular AMD" should be defined in those patients who have a persistence of exudation as evident on clinical examination and also on imaging studies (leakage on fluorescein angiography, or fibrovascular pigment epithelial detachment with intraretinal fluid [IRF] or subretinal fluid [SRF] on SD-OCT), or even increasing hemorrhage compared to the baseline after six consecutive injections at monthly intervals. Nevertheless, structural lesions that can mimic leakage on SD-OCT, such as outer retinal tubulations ${ }^{60}$ and chronic intraretinal cysts, ${ }^{61}$ are considered chronic markers of atrophy and do not require anti-VEGF treatment, which should not be considered as evidence of refractory neovascular AMD.

Our understanding of "refractory neovascular AMD" is consistent with the definition of "recalcitrant exudative AMD" by Grewal et $\mathrm{al}^{52}$ and has some characteristics in common with several experts' ideas, such as Broadhead et $\mathrm{al}^{41}$ and Fung et al. ${ }^{55}$ Broadhead et al used the term "treatmentresistant neovascular AMD" and agreed with the idea of receiving standard anti-VEGF therapy for at least 6 months to evaluate the therapeutic response. "Treatment resistance" was another description of "refractory", but Broadhead et al failed to point out whether the 6-month anti-VEGF therapy was maintained at monthly intervals or at unfixed intervals. Meanwhile, Fung et al offered a definition of "refractory CNV", which was very similar to our concept of "refractory neovascular AMD".

These experts consider the persistence of exudation after 6 months of monthly anti-VEGF therapy as an indicator of "refractory neovascular AMD" based on abundant clinical experience in practice and scientific summary from clinical trials. "Refractory AMD" is a really important concept, which contributes to finding the right time of switching treatments and making clinical decision more scientifically. Further multicentric clinical trials are needed to demonstrate that six consecutive, monthly anti-VEGF injections are a turning point of anatomical changes and/or functional changes.

\section{Recurrent neovascular AMD}

Apart from persistence of exudation, there are still patients who suffer from the appearance of new retinal hemorrhage or SRF/IRF accumulation after the initial resolution of exudative changes. Kuroda et $a l^{56}$ found that $65.7 \%$ of patients experienced a recurrence of retinal exudative change within 12 months and $74.8 \%$ reported the same within 24 months.

Yonekawa et $\mathrm{al}^{47}$ considered that "recurrent" means exudation suppressed but requiring frequent injections. In our point of view, eyes have shown complete resolution of retinal exudative change after regular anti-VEGF treatment; once the treatment is withdrawn, multiple recurrences (a minimum of two) of new or increased IRF or SRF with or without vision changes or symptoms are defined as "recurrent neovascular AMD". Our understanding of "recurrent neovascular AMD" is consistent with Arcinue et al. ${ }^{44}$ Furthermore, only one recurrence of exudation could be diagnosed as the recurrence of neovascular AMD, instead of "recurrent neovascular AMD". Recurrent retinal exudation in patients receiving uninterrupted treatment is preferable to experiencing "refractory neovascular AMD" after an initial response.

Despite multiple recurrences of exudation, some patients with recurrent neovascular AMD respond well to frequent retreatment and eventually become dry macular. However, other patients slowly become less responsive over time and maintain persistent exudation. These patients could be qualified as "refractory neovascular AMD". 


\section{Resistance to anti-VEGF therapy resulting in a diminished therapeutic effect}

Regardless of whether the diagnosis is refractory neovascular AMD or recurrent neovascular AMD, various clinical manifestations are caused by significant interindividual differences in response to an anti-VEGF agent. There is no authoritative consensus as to how to classify "responder status". Recently, Amoaku et $\mathrm{al}^{30}$ categorized the response to anti-VEGF therapies in neovascular AMD. It is divided into optimal (good) response, poor response, and nonresponse based on both functional and morphological outcomes. We consider it an appropriate definition/categorization of the response of neovascular AMD to anti-VEGF therapies. Patients who have poor response or nonresponse to anti-VEGF under the standardized treatment may gradually develop mechanisms of resistance to anti-VEGF therapy.

There is currently no consensus on the definition of "resistance to anti-VEGF therapy". Tranos et a $\mathrm{a}^{46}$ considered that half of the patients who did not improve and $\sim 10 \%$ of the patients who had no response at all despite ongoing therapies with the current standard anti-VEGF approach were resistant to anti-VEGF therapy. Bakall et a ${ }^{62}$ reported that some patients, however, had a good initial response with a resolution of fluid but then developed recurrent exudation and became resistant to further treatment. We consider patients who showed poor response or nonresponse to the initial therapy, or who had a successful initial response to anti-VEGF therapy but experienced a slow loss of response as "resistant to anti-VEGF therapy".

Some ophthalmologists make no distinction between "resistant", "refractory", and "recurrent". The term "resistant" is aimed at describing the status of a diminished therapeutic effect despite continuous treatment, while "refractory" or "recurrent" focuses on describing the characteristics of AMD itself, as previously explained. Therefore, phrases such as "resistance to anti-VEGF therapy", "refractory neovascular AMD", and "recurrent neovascular AMD" may be more useful and effective. In addition, it is also essential to distinguish "resistance to anti-VEGF therapy" and "resistance to anti-VEGF agents". The former is a broader concept that encompasses "resistance to anti-VEGF agents".

\section{Causes of resistance to anti-VEGF therapy and possible therapeutic approaches}

Resistance can occur at any time during the course of therapy. ${ }^{41}$ Anti-VEGF therapy may fail from the beginning or following an initial successful treatment period. An incomplete effect of the initial therapy may be caused by several clinical factors, including misdiagnosis and genetic predisposition. Resistance to anti-VEGF agents and sustained activation of other pathogenic pathways result in the development of persistent or recurrent exudation after an initial successful treatment period. We draw on these facets to provide a framework to show why the phenomenon of resistance to anti-VEGF therapy occurs and how to deal with it (Figure 1).

\section{An incomplete initial effect caused by clinical factors \\ Misdiagnosis}

Misdiagnosis appears to be one common clinical factor that results in poor response or nonresponse to anti-VEGF therapy.

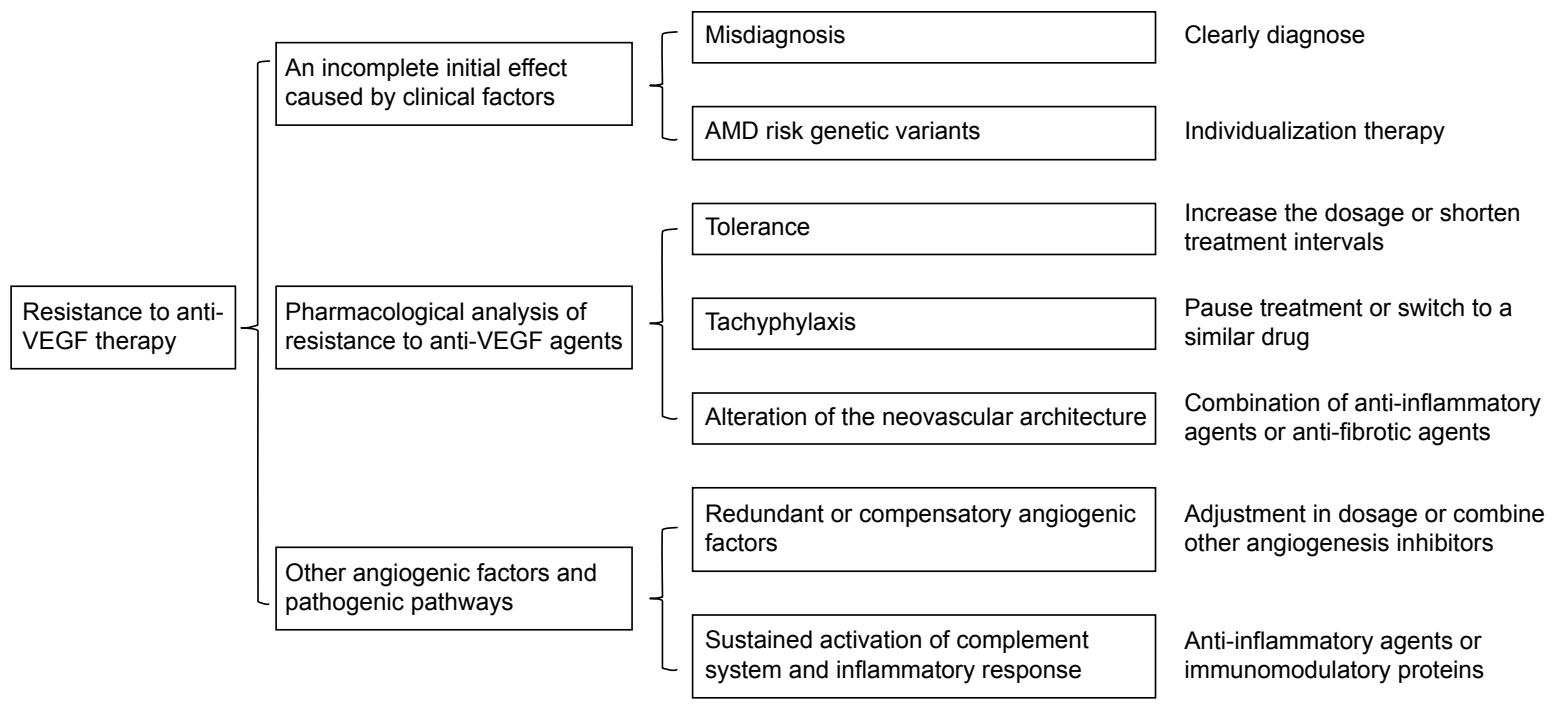

Figure I A framework to show the causes of resistance to anti-VEGF therapy and possible therapeutic approaches. Abbreviations: AMD, age-related macular degeneration; VEGF, vascular endothelial growth factor. 
Previous research has shown that $46.2 \%$ of patients with a poor response to treatment require revision of the primary diagnosis. For example, the misdiagnosis of polypoidal choroidal vasculopathy (PCV) as $\mathrm{CNV}$ and a lack of distinction between retinal angiomatous proliferation (RAP) and typical CNV have been described at length in several papers. ${ }^{40,45}$

In contrast to $\mathrm{CNV}$, which is secondary to AMD (CNVAMD) in Western populations, $\mathrm{PCV}$, an important variant of AMD, appears to be the predominant subtype of neovascular AMD in Asian populations. ${ }^{63}$ PCV may account for as high as $22.3 \%-61.6 \%{ }^{64-72}$ of cases in Asians and 8\%-13\% ${ }^{73}$ of Caucasian patients who present with presumed neovascular AMD. PCV may mimic CNV on fundus photography and fluorescence fundus angiography, further confusing the diagnosis. Focal hyperfluorescent polyps on early-phase indocyanine green angiography are still the gold standard for diagnosis. ${ }^{74}$ Considering the lower prevalence of PCV in Caucasian patients, Western ophthalmologists are relatively less experienced in its diagnosis and treatment than Asian experts. Therefore, there might be higher rates of misdiagnosis of patients with PCV in Western countries than in Asia. On the other hand, as indocyanine green angiography is not a routine examination, misdiagnosis is still common worldwide.

Because the role of VEGF in the pathogenesis of PCV is believed to be substantially less important than in $\mathrm{CNV}$, patients with PCV who are misdiagnosed for CNV may be resistant to anti-VEGF agents (ranibizumab and bevacizumab). Therefore, the diagnosis must be reevaluated, and more attention should be paid toward avoiding this misdiagnosis. If a patient has received a diagnosis of PCV, the treatment options should be changed. The optimal treatment for $\mathrm{PCV}$ requires further clarification. ${ }^{75} \mathrm{PCV}$ is usually treated with anti-VEGF monotherapy, photodynamic therapy (PDT) monotherapy, or a combination of anti-VEGF/PDT therapy, but ranibizumab and bevacizumab have limited effect on polypoidal lesions. Aflibercept, a new anti-VEGF drug, has been demonstrated to improve both visual acuity and macular morphology in a large number of treatment-naive eyes with PCV. ${ }^{76}$

RAP, which is also known as a variant of neovascular AMD, represents an estimated $10 \%-12 \%{ }^{77,78}$ of newly diagnosed neovascular AMD lesions. Freund et al ${ }^{79}$ considered RAP to be a type 3 neovascularization in order to distinguish it from the type 1 and $2 \mathrm{CNV}$ anatomic classifications. However, RAP may mimic type 1 and $2 \mathrm{CNV}$ on fluorescence fundus angiography. There is a characteristic hyperfluorescent "hot spot" in early RAP lesions on indocyanine green angiography, which has previously been considered the best approach to diagnose RAP. ${ }^{80}$ OCT angiography is a new noninvasive, motion contrast imaging modality for retinal microvasculature.
OCT angiography will play an important role in the early diagnosis of RAP to reduce the rate of misdiagnosis. ${ }^{81}$

RAP differs from typical neovascular AMD in its natural course and has previously been reported to have poor visual gain in response to anti-VEGF monotherapy. ${ }^{82-86}$ However, a subanalysis of CATT found that RAP had an optimal response to anti-VEGF therapy. ${ }^{87-89}$ Applying PDT simultaneously with intravitreal anti-VEGF agents effectively maintained or improved patients' visual acuity and reduced or eliminated edema in the short term. ${ }^{90}$

\section{AMD risk genetic variants}

AMD is influenced by both environmental and genetic factors. Numerous genetic variants, such as $C F H$, HTRA1/ $A R M S 2, C 3, C F B / C 2$, and $A P O E$ genes, confer significant risk for the development of AMD. ${ }^{91}$ However, genetic testing is not considered to be included in the standard AMD diagnosis or treatment at present. Some ophthalmologists have speculated that a genetic predisposition may also contribute to resistance to anti-VEGF therapy.

Polymorphism rs1061170 (T1277C, Y402H) has been found to be strongly associated with exudative $\mathrm{AMD}^{92}$ and $\mathrm{AMD}$ progression. ${ }^{93}$ When investigating the association between polymorphism rs1061170 and the treatment response of neovascular AMD, patients harboring homozygous for the variant risk $\mathrm{C}$-allele (CC genotype) are consistent with a decreased response to treatment by $\sim 1.6$-fold when compared to patients carrying homozygous for the ancestral T-allele (TT genotype). ${ }^{94}$ Lee et $\mathrm{a}^{95}$ found that patients harboring homozygous for the CFH Y402H risk allele had a significantly higher risk (37\%) of requiring additional ranibizumab injections. In other words, the response to treatment of AMD with ranibizumab differed according to the patient's specific CFH genotype.

As for $A R M S 2$ gene, Abedi et al ${ }^{96}$ found single nucleotide polymorphism rs10490924 (A69S) in the LOC387715/ ARMS2 gene with poor outcome of intravitreal antiVEGF injections in neovascular AMD. A literature-based meta-analysis was performed of studies relevant to A69S polymorphism in the $A R M S 2$ gene and the response to antiangiogenesis treatment by $\mathrm{Hu}$ et al. ${ }^{97}$ They also found A69S could be considered predictive of the anti-angiogenic effects, especially in Asian populations. ${ }^{97}$

These patients with AMD risk genetic variants might have higher background levels of inflammation, which may continue to affect the disease progression and probably lead to a more rapid recurrence of neovascularization, which produces a diminished therapeutic effect. ${ }^{95}$ It is conceivable that future AMD treatments may depend on the patient's individual genetic risk profile to develop individualized 
therapy. ${ }^{98}$ For example, intravitreal exogenous $\mathrm{CFH}$ or CFH-related complement inhibitors may be a beneficial therapy for patients with polymorphism rs 1061170 .

\section{Pharmacological analysis of resistance to anti-VEGF agents \\ Tolerance}

Drug tolerance is a pharmacology concept, where a subject's reaction to a specific drug and the physiological concentration of the drug are reduced followed by repeated use, subsequently requiring an increased dosage or shorter dosing time intervals to achieve the desired effect. ${ }^{99}$ However, efficacy is not restored even when the treatment is halted temporarily. ${ }^{100}$ Drug tolerance could be divided into several different types, including pharmacodynamic tolerance, pharmacokinetic (metabolic) tolerance, and behavioral tolerance (for certain psychoactive drugs).

During anti-VEGF therapies, pharmacodynamic tolerance may be caused by the increased expression of VEGF (especially derived from those macrophages that locate within the choroidal neovascular tissue and respond to VEGF inhibition by upregulating the production of VEGF itself), increased expression of VEGF receptors, changes in signal transduction, or a shift of the stimulus for CNV growth toward other growth factors. ${ }^{34}$ Pharmacokinetic tolerance occurs because a decreased quantity of the substance reaches the site it affects. A systemic immune response, the development of neutralizing antibodies, ${ }^{34}$ increased clearance from the eye, or reflux of the drug following injection may all result in pharmacokinetic tolerance. The Biologics License Application states that the baseline incidence of immunoreactivity to ranibizumab is $0 \%-3 \%$, which rises to $\sim 1 \%-6 \%$ after monthly dosing with ranibizumab for 12-24 months based on 1-year clinical efficacy and safety data from two pivotal Phase III trials, ANCHOR and MARINA, and the Phase I-II FOCUS trial. ${ }^{36}$ Theoretically, it is therefore necessary to increase the dosage or shorten treatment intervals if tolerance has developed.

Several studies have investigated the relationship between increasing the dose and further anatomical and visual outcomes. The HARBOR trial ${ }^{101}$ and Forooghian et al's ${ }^{36}$ study demonstrated that high-dose ranibizumab/bevacizumab given monthly did not restore therapeutic responses in eyes that had developed a tolerance, while the evaluation of high-dose ranibizumab $(2.0 \mathrm{mg})$ in the management of AMD in patients with persistent/recurrent macular fluid (LAST) study ${ }^{55}$ and Brown et al' $\mathrm{s}^{51}$ trial found that $2.0 \mathrm{mg}$ of ranibizumab could maintain anatomical results and preserve or improve best-corrected visual acuity in patients with persistent or recurrent SRF or IRF despite previous standard anti-VEGF therapy. Compared to Forooghian et al's study, the LAST study, and Brown et al's trial, the conclusion of the HARBOR trial may be more persuasive because of that study's relatively larger sample. The study indicated that intravitreal high-dose anti-VEGF agents may not be readily effective at restoring a complete therapeutic response in all patients. Apart from unclear efficacy, the treatment is also an economic burden for patients when the dosage is increased, which makes it difficult to apply in clinical practice.

Few large trials have evaluated the effect of increasing the frequency of treatment to more than once a month. Stewart et a ${ }^{102}$ found that dosing a drug (ranibizumab, bevacizumab, and aflibercept) every 2 weeks resulted in markedly improved trough binding activity, so the short-term use of biweekly dosing may be an attractive treatment option for those eyes that respond within 2 weeks of an injection but then rebound with increased macular fluid after a month. Treatment every 2 weeks may present a challenge for patients with poor compliance and also carries a significant cost implication. Moreover, shorter dosing time intervals of every 2 weeks have not yet been approved by the FDA for neovascular AMD.

\section{Tachyphylaxis}

Tachyphylaxis is a medical term describing an acute (sudden) decrease in the response to a drug after its administration. ${ }^{103}$ It can occur after an initial dose or following a series of small doses. Keane et al ${ }^{104}$ was the first to suggest that possible tachyphylaxis had appeared after treatment with ranibizumab, while other researchers have considered that tachyphylaxis may occur as early as after two injections. ${ }^{37-39,105}$ Tachyphylaxis cannot be overcome by increasing the dosage. However, efficacy can be restored if the medication is stopped for a short while or if the interval between doses is increased. However, the mechanism of tachyphylaxis during anti-VEGF therapies for exudative AMD is still not clear.

If tachyphylaxis occurs, clinicians should stop the treatment for a while or switch to a similar drug with different properties. ${ }^{34}$ The majority of these therapies involve switching patients from bevacizumab to ranibizumab, ${ }^{37,106-109}$ from ranibizumab to bevacizumab, ${ }^{37,105,107-110}$ and from bevacizumab/ranibizumab to aflibercept. ${ }^{42,43,47,52,62,111-119}$

The proposed mechanism of switching between two antiVEGF drugs, bevacizumab and ranibizumab, could be due to the different molecular sizes and associated transport of these molecules through the retina and into the subretinal space. Ranibizumab was found diffusely across the retina after intravitreal injection because of its smaller size. Bevacizumab may also reach the subretinal space with a different distribution in 
the retina after intravitreal injection. ${ }^{120}$ Aflibercept is a novel VEGF inhibitor with a higher binding efficacy and a wider spectrum of action than both bevacizumab and ranibizumab. ${ }^{21}$ Aflibercept may help patients with persistent fluid despite standard treatment with ranibizumab and bevacizumab. Fourteen trials have all demonstrated that patients who are resistant to ranibizumab or bevacizumab have a therapeutic, anatomical structure response when switched to aflibercept, but only five of them ${ }^{43,111-113,118}$ experienced improved visual outcomes.

Conbercept has a similar molecular structure to that of aflibercept, which is also a recombinant fusion protein of the ligand-binding elements of VEGF receptors. ${ }^{22}$ Conbercept was approved by the China FDA in December 2013 and has not yet reached the market in other countries. Therefore, there was no evidence to verify the efficacy of switching to conbercept when tachyphylaxis occurs. Given its similar structure to aflibercept, excellent safety and efficacy profile, conbercept is expected to be effective for such patients, but further investigation is needed.

\section{Alteration of the neovascular architecture}

Vascular endothelial cells (ECs) play a crucial role in vascular formation. EC mutations may potentially lead to conformational changes in receptors and affect the expression profile and the resultant sensitivity to available antiangiogenic agents. ${ }^{121}$ In addition, anti-VEGF therapy may promote apoptosis of ECs, leading to empty vascular sleeves formed by the persistence of pericytes and the vascular basement membrane. These empty vascular sleeves serve as channels for EC proliferation when anti-VEGF therapy is halted, ${ }^{122}$ which might be one of the reasons for the regression of $\mathrm{CNV}$.

Oncologists have demonstrated that tumor vessels have enhanced vessel diameter, mature pericytes, immunoreactivity for desmin, platelet-derived growth factor receptor- $\beta$, and late-stage maturity marker $\alpha$ smooth muscle actin to enhance vascular maturity during antiangiogenic blockade. Prolonged antiangiogenesis significantly alters the expression of angiogenic factors implicated in vascular mural cell recruitment, causing extensive morphological changes in the vessels. ${ }^{123} \mathrm{We}$ could speculate that there may be similar changes in $\mathrm{CNV}$ architecture during prolonged antiangiogenic blockade, which forms a complicated barrier to current therapy.

Chronic inflammation may cause permanent structural damage to the vascular walls of the CNV complex, which could conceivably result in permanent abnormal vascular permeability and persistent exudation that is no longer amenable to anti-VEGF therapy. ${ }^{101}$ Inflammatory stimulation could also increase fibrosis of the CNV, which acts as a resorption barrier and decreases patients' sensitivity to antiVEGF drugs.

Mutations in ECs, maintenance of vascular sleeves, vascular remodeling, and chronic inflammatory changes of CNV can be influential in their therapeutic effects. There is currently still no effective therapy for EC mutations and apoptosis during antiangiogenic therapy. However, the combination of anti-inflammatory agents or anti-fibrotic agents might play a role in delaying the process of chronic inflammatory changes of CNV.

\section{Various redundant proangiogenic factors and other pathogenic pathways Redundant or compensatory angiogenic factors}

Although VEGF is a key driver of the formation of $\mathrm{CNV}$, many other proangiogenic factors could also promote angiogenesis, such as fibroblast growth factor, transforming growth factor, tumor necrosis factor, interleukins, platelet-derived growth factor (PDGF), and placenta growth factor. VEGF signaling might be closely linked to other pathways, such as PDGF $^{124,125}$ and fibroblast growth factor ${ }^{126,127}$ signaling. An increase in the expression of these factors may possibly fuel alternate signaling pathways for angiogenesis, which could trigger VEGF-independent neovascularization and cause resistance to mono anti-VEGF drugs.

Treatment may require dynamic adjustment in the dosage of the therapy or a combination with other angiogenesis inhibitors, such as anti-PDGF agents. PDGF participates in the recruitment of pericytes; thus, anti-PDGF therapy could prevent the pericytes from protecting the vessels, possibly increasing neovascular sensitivity to anti-VEGF therapy. ${ }^{128}$ Fovista is an anti-PDGF agent. A Phase IIb clinical trial has demonstrated that patients who received ranibizumab combined with Fovista obtained a significantly higher final visual acuity than those administered ranibizumab monotherapy. A Phase III randomized, double-blind, controlled trial is underway.

\section{Sustained activation of the complement system and inflammatory response}

In addition to angiogenesis, complement activation and inflammation have also been implicated in the pathogenesis of AMD. Anti-VEGF therapy can only inhibit VEGF-induced neovascularization, but sustained activation of the complement system and inflammatory response may reduce the sensibility to anti-VEGF agents.

Neovascular AMD, with its various pathogens and multiple pathogenic mechanisms, is a complicated disease that requires multi-targeted and comprehensive treatment, such as 
a combination of anti-inflammatory agents or immunomodulatory proteins. Triamcinolone is a long-acting synthetic corticosteroid that has been used intravitreally to reduce macular edema. Schaal et $\mathrm{al}^{39}$ have found that the combination of triamcinolone acetate and anti-VEGF therapy may lessen the effect of decreased bioefficacy after repeated intravitreal injections. Tandospirone, a serotonin receptor agonist, has a local neuroprotective, anti-inflammatory effect and is being investigated at present. Complement system-modulating substances, such as antibodies (LFG316, FCFD4514S, eculizumab), peptides (POT-4), aptamers (ARC1905), and antibody fragments (lampalizumab), show promising prospects in AMD therapy. ${ }^{98}$

\section{Conclusion}

Five anti-VEGF agents have been introduced in the field of ophthalmology since 2004. These agents have brought dramatic changes in the treatment of neovascular AMD, with fewer patients losing their vision and a reasonable proportion showing vision improvement. Despite the outstanding advances made by anti-VEGF therapy, most patients require repeated injections frequently and long-term follow-up regularly. The SEVEN-UP study ${ }^{129}$ showed that the mean visual acuity gradually decreased during long-term follow-up with retreatment using a pro re nata regimen when patients exited from the MARINA or ANCHOR trial. These findings indicated that anti-VEGF therapy is a long and arduous process. Emerging terms such as "refractory neovascular AMD" and "recurrent neovascular AMD" are widely used today. As novel anti-VEGF agents, aflibercept and conbercept have a higher binding efficacy and a wider spectrum of action than both bevacizumab and ranibizumab. ${ }^{21,22}$ Switching to aflibercept or conbercept may be effective for patients resistant to treatment with bevacizumab or ranibizumab. To consolidate and define these concepts is of great importance in clinical decision making with regard to the switching opportunity and also an evaluation of its effects.

We have to realize that beyond VEGF, there are still abundant angiogenic signaling cascade and other pathways that are related to the pathophysiology of neovascular AMD altogether. Many investigational drugs have the potential to not only reduce patient visits and injections but also improve outcomes by targeting additional pathways, increasing the target's affinity, and lengthening treatment durability. ${ }^{128}$ Insight into the mechanisms of resistance to anti-VEGF therapy would be helpful to guiding treatment decisions regarding when to switch to other anti-VEGF drugs or choose a combination therapy or multi-target treatment, which will be a real breakthrough in the treatment of neovascular AMD.

\section{Acknowledgment}

This study was supported by grants from the National Science Foundation for Distinguished Young Scholars (81425006).

\section{Disclosure}

Dr Sun is a consultant to Novartis International AG (Basel, Switzerland) and Chengdu Kanghong Biotechnology Co. Ltd. (Chengdu, People's Republic of China). This review received no specific grant from any funding agency in either the commercial or not-for-profit sectors. The authors report no other conflicts of interest in this work.

\section{References}

1. WHO [webpage on the Internet]. Prevention of Blindness and Visual Impairment. Priority Eye Diseases; 2012. Available from: http://www.who. int/blindness/causes/priority/en/index 7.html. Accessed May 6, 2016.

2. Lim LS, Mitchell P, Seddon JM, Holz FG, Wong TY. Age-related macular degeneration. Lancet. 2012;379(9827):1728-1738.

3. Campa $\mathrm{C}$, Costagliola $\mathrm{C}$, Incorvaia $\mathrm{C}$, et al. Inflammatory mediators and angiogenic factors in choroidal neovascularization: pathogenetic interactions and therapeutic implications. Mediators Inflamm. 2010;2010:14.

4. Spilsbury K, Garrett KL, Shen WY, Constable IJ, Rakoczy PE. Overexpression of vascular endothelial growth factor (VEGF) in the retinal pigment epithelium leads to the development of choroidal neovascularization. Am J Pathol. 2000;157(1):135-144.

5. Ishibashi T, Hata Y, Yoshikawa H, Nakagawa K, Sueishi K, Inomata H. Expression of vascular endothelial growth factor in experimental choroidal neovascularization. Graefes Arch Clin Exp Ophthalmol. 1997; 235(3):159-167.

6. Wong TY, Liew G, Mitchell P. Clinical update: new treatments for age-related macular degeneration. Lancet. 2007;370(9583):204-206.

7. Brown DM, Kaiser PK, Michels M, et al. Ranibizumab versus verteporfin for neovascular age-related macular degeneration. NEngl J Med. 2006;355(14):1432-1444.

8. Gragoudas ES, Adamis AP, Cunningham ET Jr, Feinsod M, Guyer DR; VEGF Inhibition Study in Ocular Neovascularization Clinical Trial Group. Pegaptanib for neovascular age-related macular degeneration. N Engl J Med. 2004;351(27):2805-2816.

9. Group CR, Martin DF, Maguire MG, et al. Ranibizumab and bevacizumab for neovascular age-related macular degeneration. N Engl J Med. 2011;364(20):1897-1908

10. Rosenfeld PJ, Brown DM, Heier JS, et al; MARINA Study Group. Ranibizumab for neovascular age-related macular degeneration. $N$ Engl J Med. 2006;355(14):1419-1431.

11. Comparison of Age-related Macular Degeneration Treatments Trials Research Group, Martin DF, Maguire MG, et al. Ranibizumab and bevacizumab for treatment of neovascular age-related macular degeneration: two-year results. Ophthalmology. 2012;119(7):1388-1398.

12. Heier JS, Brown DM, Chong V, et al; Schmidt-Erfurth U; VIEW 1 and VIEW 2 Study Groups. Intravitreal aflibercept (VEGF trap-eye) in wet age-related macular degeneration. Ophthalmology. 2012;119(12): 2537-2548.

13. Li X, Xu G, Wang Y, et al; AURORA Study Group. Safety and efficacy of conbercept in neovascular age-related macular degeneration: results from a 12-month randomized phase 2 study: AURORA study. Ophthalmology. 2014;121(9):1740-1747.

14. Ruckman J, Green LS, Beeson J, et al. 2'-Fluoropyrimidine RNA-based aptamers to the 165-amino acid form of vascular endothelial growth factor (VEGF165). Inhibition of receptor binding and VEGF-induced vascular permeability through interactions requiring the exon 7-encoded domain. J Biol Chem. 1998;273(32):20556-20567.

15. Criswell MH, Hu WZ, Steffens TJ, Li R, Margaron P. Comparing pegaptanib and triamcinolone efficacy in the rat choroidal neovascularization model. Arch Ophthalmol. 2008;126(7):946-952. 
16. Morjaria R, Chong NV. Pharmacokinetic evaluation of pegaptanib octasodium for the treatment of diabetic edema. Expert Opin Drug Metab Toxicol. 2014;10(8):1185-1192.

17. Bakri SJ, Snyder MR, Reid JM, Pulido JS, Ezzat MK, Singh RJ. Pharmacokinetics of intravitreal ranibizumab (Lucentis). Ophthalmology. 2007;114(12):2179-2182.

18. Bakri SJ, Snyder MR, Reid JM, Pulido JS, Singh RJ. Pharmacokinetics of intravitreal bevacizumab (Avastin). Ophthalmology. 2007;114(5) 855-859.

19. Papadopoulos N, Martin J, Ruan Q, et al. Binding and neutralization of vascular endothelial growth factor (VEGF) and related ligands by VEGF Trap, ranibizumab and bevacizumab. Angiogenesis. 2012;15(2): $171-185$.

20. Investigators IS, Chakravarthy U, Harding SP, et al. Ranibizumab versus bevacizumab to treat neovascular age-related macular degeneration one-year findings from the IVAN randomized trial. Ophthalmology. 2012;119(7):1399-1411.

21. Stewart MW, Rosenfeld PJ. Predicted biological activity of intravitreal VEGF Trap. Br J Ophthalmol. 2008;92(5):667-668.

22. Lu X, Sun X. Profile of conbercept in the treatment of neovascular age-related macular degeneration. Drug Des Devel Ther. 2015;9: 2311-2320.

23. Holash J, Davis S, Papadopoulos N, et al. VEGF-Trap: a VEGF blocker with potent antitumor effects. Proc Natl Acad Sci US A. 2002; 99(17):11393-11398.

24. Zhang M, Yu D, Yang C, et al. The pharmacology study of a new recombinant human VEGF receptor-fc fusion protein on experimental choroidal neovascularization. Pharm Res. 2009;26(1):204-210.

25. Wu Z, Zhou P, Li X, et al. Structural characterization of a recombinant fusion protein by instrumental analysis and molecular modeling. PLoS One. 2013;8(3):e57642.

26. Bloch SB, Larsen M, Munch IC. Incidence of legal blindness from age-related macular degeneration in Denmark: year 2000 to 2010 Am J Ophthalmol. 2012;153(2):209-213.e202.

27. Skaat A, Chetrit A, Belkin M, Kinori M, Kalter-Leibovici O. Time trends in the incidence and causes of blindness in Israel. Am J Ophthalmol. 2012;153(2):214-221.e211.

28. Sloan FA, Hanrahan BW. The effects of technological advances on outcomes for elderly persons with exudative age-related macular degeneration. JAMA Ophthalmol. 2014;132(4):456-463.

29. Wykoff CC, Brown DM, Maldonado ME, Croft DE. Aflibercept treatment for patients with exudative age-related macular degeneration who were incomplete responders to multiple ranibizumab injections (TURF trial). Br J Ophthalmol. 2014;98(7):951-955.

30. Amoaku WM, Chakravarthy U, Gale R, et al. Defining response to anti-VEGF therapies in neovascular AMD. Eye (Lond). 2015;29(6): 721-731.

31. van Asten F, Rovers MM, Lechanteur YT, et al. Predicting non-response to ranibizumab in patients with neovascular age-related macular degeneration. Ophthalmic Epidemiol. 2014;21(6):347-355.

32. Yazdi MH, Faramarzi MA, Nikfar S, Falavarjani KG, Abdollahi M. Ranibizumab and aflibercept for the treatment of wet age-related macular degeneration. Expert Opin Biol Ther. 2015;15(9):1349-1358.

33. Li H, Lei N, Zhang M, Li Y, Xiao H, Hao X. Pharmacokinetics of a long-lasting anti-VEGF fusion protein in rabbit. Exp Eye Res. 2012; 97(1):154-159.

34. Binder S. Loss of reactivity in intravitreal anti-VEGF therapy: tachyphylaxis or tolerance? Br J Ophthalmol. 2012;96(1):1-2.

35. Arjamaa O, Minn H. Resistance, not tachyphylaxis or tolerance. $\mathrm{Br} J$ Ophthalmol. 2012;96(8):1153-1154

36. Forooghian F, Cukras C, Meyerle CB, Chew EY, Wong WT. Tachyphylaxis after intravitreal bevacizumab for exudative age-related macular degeneration. Retina. 2009;29(6):723-731.

37. Gasperini JL, Fawzi AA, Khondkaryan A, et al. Bevacizumab and ranibizumab tachyphylaxis in the treatment of choroidal neovascularisation. Br J Ophthalmol. 2012;96(1):14-20.

38. Avgikos KN, Horgan SE, Sivaraj RR, Hu K. Tachyphylaxis and bevacizumab. Ophthalmology. 2009;116(9):1831-1832. [author reply 1832].
39. Schaal S, Kaplan HJ, Tezel TH. Is there tachyphylaxis to intravitreal anti-vascular endothelial growth factor pharmacotherapy in age-related macular degeneration? Ophthalmology. 2008;115(12):2199-2205.

40. Eghoj MS, Sorensen TL. Tachyphylaxis during treatment of exudative age-related macular degeneration with ranibizumab. Br J Ophthalmol. 2012;96(1):21-23

41. Broadhead GK, Hong T, Chang AA. Treating the untreatable patient: current options for the management of treatment-resistant neovascular age-related macular degeneration. Acta Ophthalmol. 2014;92(8): 713-723.

42. Gharbiya M, Iannetti L, Parisi F, De Vico U, Mungo ML, Marenco M. Visual and anatomical outcomes of intravitreal aflibercept for treatmentresistant neovascular age-related macular degeneration. Biomed Res Int. 2014;2014:273754.

43. Chang AA, Li H, Broadhead GK, et al. Intravitreal aflibercept for treatmentresistant neovascular age-related macular degeneration. Ophthalmology. 2014;121(1):188-192.

44. Arcinue CA, Ma F, Barteselli G, Sharpsten L, Gomez ML, Freeman WR. One-year outcomes of aflibercept in recurrent or persistent neovascular age-related macular degeneration. Am J Ophthalmol. 2015;159(3): 426-436.e422.

45. Moon da RC, Lee DK, Kim SH, You YS, Kwon OW. Aflibercept treatment for neovascular age-related macular degeneration and polypoidal choroidal vasculopathy refractory to anti-vascular endothelial growth factor. Korean J Ophthalmol. 2015;29(4):226-232.

46. Tranos P, Vacalis A, Asteriadis S, et al. Resistance to antivascular endothelial growth factor treatment in age-related macular degeneration. Drug Des Devel Ther. 2013;7:485-490.

47. Yonekawa Y, Andreoli C, Miller JB, et al. Conversion to aflibercept for chronic refractory or recurrent neovascular age-related macular degeneration. Am J Ophthalmol. 2013;156(1):29-35.e22.

48. Shin JY, Woo SJ, Ahn J, Park KH. Anti-VEGF-refractory exudative age-related macular degeneration: differential response according to features on optical coherence tomography. Korean J Ophthalmol. 2013; 27(6):425-432.

49. Hirano Y, Yasukawa T, Tsukada A, Yokoyama S, Ito Y, Nakazawa Y. Resolution of exudative changes refractory to ranibizumab after aflibercept injections at the margin of inferior staphyloma in tilted disc syndrome. Ophthalmic Surg Lasers Imaging Retina. 2015;46(3): 384-386.

50. Cho M, Barbazetto IA, Freund KB. Refractory neovascular age-related macular degeneration secondary to polypoidal choroidal vasculopathy. Am J Ophthalmol. 2009;148(1):70-78.e71.

51. Brown DM, Chen E, Mariani A, Major JC Jr, Group SS. Super-dose antiVEGF (SAVE) trial: $2.0 \mathrm{mg}$ intravitreal ranibizumab for recalcitrant neovascular macular degeneration-primary end point. Ophthalmology. 2013;120(2):349-354.

52. Grewal DS, Gill MK, Sarezky D, Lyon AT, Mirza RG. Visual and anatomical outcomes following intravitreal aflibercept in eyes with recalcitrant neovascular age-related macular degeneration: 12-month results. Eye (Lond). 2014;28(7):895-899.

53. Puliafito CA. Recalcitrant neovascular macular degeneration after anti-VEGF therapy: an ongoing challenge. Ophthalmic Surg Lasers Imaging Retina. 2013;44(2):109.

54. Kanesa-Thasan A, Grewal DS, Gill MK, Lyon AT, Mirza RG. Quantification of change in pigment epithelial detachment volume and morphology after transition to intravitreal aflibercept in eyes with recalcitrant neovascular AMD: 18-month results. Ophthalmic Surg Lasers Imaging Retina. 2015;46(6):638-641.

55. Fung AT, Kumar N, Vance SK, et al. Pilot study to evaluate the role of high-dose ranibizumab $2.0 \mathrm{mg}$ in the management of neovascular age-related macular degeneration in patients with persistent/recurrent macular fluid $<30$ days following treatment with intravitreal anti-VEGF therapy (the LAST Study). Eye (Lond). 2012;26(9):1181-1187.

56. Kuroda Y, Yamashiro K, Miyake M, et al. Factors associated with recurrence of age-related macular degeneration after anti-vascular endothelial growth factor treatment: a retrospective cohort study. Ophthalmology. 2015;122(11):2303-2310. 
57. Joondeph BC. Anti-vascular endothelial growth factor injection technique for recurrent exudative macular degeneration in a telescopeimplanted eye. Retin Cases Brief Rep. 2014;8(4):342-344.

58. Pinheiro-Costa J, Costa JM, Beato JN, et al. Switch to aflibercept in the treatment of neovascular AMD: one-year results in clinical practice. Ophthalmologica. 2015;233(3-4):155-161.

59. Tozer K, Roller AB, Chong LP, et al. Combination therapy for neovascular age-related macular degeneration refractory to anti-vascular endothelial growth factor agents. Ophthalmology. 2013;120(10):2029-2034.

60. Zweifel SA, Engelbert M, Laud K, Margolis R, Spaide RF, Freund KB. Outer retinal tubulation: a novel optical coherence tomography finding. Arch Ophthalmol. 2009;127(12):1596-1602.

61. Wolff B, Maftouhi MQ, Mateo-Montoya A, Sahel JA, Mauget-Faysse M. Outer retinal cysts in age-related macular degeneration. Acta Ophthalmol. 2011;89(6):e496-e499.

62. Bakall B, Folk JC, Boldt HC, et al. Aflibercept therapy for exudative age-related macular degeneration resistant to bevacizumab and ranibizumab. Am J Ophthalmol. 2013;156(1):15-22.e11.

63. Lim LS, Cheung CM, Wong TY. Asian age-related macular degeneration: current concepts and gaps in knowledge. Asia Pac J Ophthalmol (Phila). 2013;2(1):32-41.

64. Chang YC, Wu WC. Polypoidal choroidal vasculopathy in Taiwanese patients. Ophthalmic Surg Lasers Imaging. 2009;40(6):576-581.

65. Wen F, Chen C, Wu D, Li H. Polypoidal choroidal vasculopathy in elderly Chinese patients. Graefes Arch Clin Exp Ophthalmol. 2004;242(8): 625-629.

66. Liu Y, Wen F, Huang S, et al. Subtype lesions of neovascular agerelated macular degeneration in Chinese patients. Graefes Arch Clin Exp Ophthalmol. 2007;245(10):1441-1445.

67. Sho K, Takahashi K, Yamada H, et al. Polypoidal choroidal vasculopathy: incidence, demographic features, and clinical characteristics. Arch Ophthalmol. 2003;121(10):1392-1396.

68. Coscas G, Yamashiro K, Coscas F, et al. Comparison of exudative agerelated macular degeneration subtypes in Japanese and French Patients: multicenter diagnosis with multimodal imaging. Am J Ophthalmol.2014; 158(2):309-318.e302.

69. Maruko I, Iida T, Saito M, Nagayama D, Saito K. Clinical characteristics of exudative age-related macular degeneration in Japanese patients. Am J Ophthalmol. 2007;144(1):15-22.

70. Byeon SH, Lee SC, Oh HS, Kim SS, Koh HJ, Kwon OW. Incidence and clinical patterns of polypoidal choroidal vasculopathy in Korean patients. Jpn J Ophthalmol. 2008;52(1):57-62.

71. Cheung CM, Li X, Mathur R, et al. A prospective study of treatment patterns and 1-year outcome of Asian age-related macular degeneration and polypoidal choroidal vasculopathy. PLoS One. 2014;9(6):e101057.

72. Mori K, Horie-Inoue K, Gehlbach PL, et al. Phenotype and genotype characteristics of age-related macular degeneration in a Japanese population. Ophthalmology. 2010;117(5):928-938.

73. Ciardella AP, Donsoff IM, Huang SJ, Costa DL, Yannuzzi LA. Polypoidal choroidal vasculopathy. Surv Ophthalmol. 2004;49(1):25-37.

74. Ciardella AP, Donsoff IM, Yannuzzi LA. Polypoidal choroidal vasculopathy. Ophthalmol Clin North Am. 2002;15(4):537-554.

75. Wong CW, Wong TY, Cheung CM. Polypoidal choroidal vasculopathy in Asians. J Clin Med. 2015;4(5):782-821.

76. Yamamoto A, Okada AA, Kano M, et al. One-Year results of intravitreal aflibercept for polypoidal choroidal vasculopathy. Ophthalmology. 2015; 122(9): 1866-1872.

77. Kuhn D, Meunier I, Soubrane G, Coscas G. Imaging of chorioretinal anastomoses in vascularized retinal pigment epithelium detachments. Arch Ophthalmol. 1995;113(11):1392-1398.

78. Freund KB, Klais CM, Eandi CM, et al. Sequenced combined intravitreal triamcinolone and indocyanine green angiography-guided photodynamic therapy for retinal angiomatous proliferation. Arch Ophthalmol. 2006;124(4):487-492.

79. Freund KB, Ho IV, Barbazetto IA, et al. Type 3 neovascularization: the expanded spectrum of retinal angiomatous proliferation. Retina. 2008; 28(2):201-211.
80. Yannuzzi LA, Freund KB, Takahashi BS. Review of retinal angiomatous proliferation or type 3 neovascularization. Retina. 2008;28(3): 375-384.

81. Dansingani KK, Naysan J, Freund KB. En face OCT angiography demonstrates flow in early type 3 neovascularization (retinal angiomatous proliferation). Eye (Lond). 2015;29(5):703-706.

82. Hartnett ME, Weiter JJ, Staurenghi G, Elsner AE. Deep retinal vascular anomalous complexes in advanced age-related macular degeneration. Ophthalmology. 1996;103(12):2042-2053.

83. Bottoni F, Massacesi A, Cigada M, Viola F, Musicco I, Staurenghi G. Treatment of retinal angiomatous proliferation in age-related macular degeneration: a series of 104 cases of retinal angiomatous proliferation. Arch Ophthalmol. 2005;123(12):1644-1650.

84. Bressler NM. Retinal anastomosis to choroidal neovascularization: a bum rap for a difficult disease. Arch Ophthalmol. 2005;123(12): 1741-1743.

85. Hemeida TS, Keane PA, Dustin L, Sadda SR, Fawzi AA. Long-term visual and anatomical outcomes following anti-VEGF monotherapy for retinal angiomatous proliferation. Br J Ophthalmol. 2010;94(6): 701-705.

86. Rouvas AA, Chatziralli IP, Theodossiadis PG, Moschos MM, Kotsolis AI, Ladas ID. Long-term results of intravitreal ranibizumab, intravitreal ranibizumab with photodynamic therapy, and intravitreal triamcinolone with photodynamic therapy for the treatment of retinal angiomatous proliferation. Retina. 2012;32(6):1181-1189.

87. Scott AW, Bressler SB. Retinal angiomatous proliferation or retinal anastomosis to the lesion. Eye (Lond). 2010;24(3):491-496.

88. Ying GS, Huang J, Maguire MG, et al; Comparison of Age-related Macular Degeneration Treatments Trials Research Group. Baseline predictors for one-year visual outcomes with ranibizumab or bevacizumab for neovascular age-related macular degeneration. Ophthalmology. 2013;120(1):122-129.

89. Gharbiya M, Parisi F, Cruciani F, Bozzoni-Pantaleoni F, Pranno F, Abdolrahimzadeh S. Intravitreal anti-vascular endothelial growth factor for retinal angiomatous proliferation in treatment-naive eyes: long-term functional and anatomical results using a modified PrONTO-style regimen. Retina. 2014;34(2):298-305.

90. Saito M, Shiragami C, Shiraga F, Nagayama D, Iida T. Combined intravitreal bevacizumab and photodynamic therapy for retinal angiomatous proliferation. Am J Ophthalmol. 2008;146(6):935-941.e931.

91. Chamberlain M, Baird P, Dirani M, Guymer R. Unraveling a complex genetic disease: age-related macular degeneration. Surv Ophthalmol. 2006;51(6):576-586.

92. Souied EH, Leveziel N, Richard F, et al. Y402H complement factor H polymorphism associated with exudative age-related macular degeneration in the French population. Mol Vis. 2005;11:1135-1140.

93. Seddon JM, Francis PJ, George S, Schultz DW, Rosner B, Klein ML. Association of CFH Y402H and LOC387715 A69S with progression of age-related macular degeneration. JAMA. 2007;297(16):1793-1800.

94. Chen H, Yu KD, Xu GZ. Association between variant Y402H in agerelated macular degeneration (AMD) susceptibility gene $\mathrm{CFH}$ and treatment response of AMD: a meta-analysis. PLoS One. 2012;7(8): e42464.

95. Lee AY, Raya AK, Kymes SM, Shiels A, Brantley MA Jr. Pharmacogenetics of complement factor $\mathrm{H}(\mathrm{Y} 402 \mathrm{H})$ and treatment of exudative age-related macular degeneration with ranibizumab. Br J Ophthalmol. 2009;93(5):610-613.

96. Abedi F, Wickremasinghe S, Richardson AJ, Islam AF, Guymer RH, Baird PN. Genetic influences on the outcome of anti-vascular endothelial growth factor treatment in neovascular age-related macular degeneration. Ophthalmology. 2013;120(8):1641-1648.

97. Hu Z, Xie P, Ding Y, Yuan D, Liu Q. Association between variants A69S in ARMS2 gene and response to treatment of exudative AMD: a meta-analysis. Br J Ophthalmol. 2015;99(5):593-598.

98. Weber BH, Charbel Issa P, Pauly D, Herrmann P, Grassmann F, Holz FG. The role of the complement system in age-related macular degeneration. Dtsch Arztebl Int. 2014;111(8):133-138. 
99. Rogers FB. Medical subject headings. Bull Med Libr Assoc. 1963;51: 114-116.

100. Westfall TC, Westfall DP. Goodman and Gilman's. The Pharmacological Basis of Therapeutics. 12th ed. New York, NY: McGraw-Hill; 2011.

101. Busbee BG, Ho AC, Brown DM, et al. Twelve-month efficacy and safety of $0.5 \mathrm{mg}$ or $2.0 \mathrm{mg}$ ranibizumab in patients with subfoveal neovascular age-related macular degeneration. Ophthalmology. 2013; 120(5):1046-1056.

102. Stewart MW, Rosenfeld PJ, Penha FM, et al. Pharmacokinetic rationale for dosing every 2 weeks versus 4 weeks with intravitreal ranibizumab, bevacizumab, and aflibercept (vascular endothelial growth factor Trap-eye). Retina. 2012;32(3):434-457.

103. Bunnel CA. Intensive Review of Internal Medicine. Boston, MA: Harvard Medical School; 2009

104. Keane PA, Liakopoulos S, Ongchin SC, et al. Quantitative subanalysis of optical coherence tomography after treatment with ranibizumab for neovascular age-related macular degeneration. Invest Ophthalmol Vis Sci. 2008;49(7):3115-3120.

105. Almony A, Mansouri A, Shah GK, Blinder KJ. Efficacy of intravitreal bevacizumab after unresponsive treatment with intravitreal ranibizumab. Can J Ophthalmol. 2011;46(2):182-185.

106. Kent JS, Iordanous Y, Mao A, Powell AM, Kent SS, Sheidow TG Comparison of outcomes after switching treatment from intravitreal bevacizumab to ranibizumab in neovascular age-related macular degeneration. Can J Ophthalmol. 2012;47(2):159-164.

107. Kaiser RS, Gupta OP, Regillo CD, et al. Ranibizumab for eyes previously treated with pegaptanib or bevacizumab without clinical response. Ophthalmic Surg Lasers Imaging. 2012;43(1):13-19.

108. Ehlken C, Jungmann S, Bohringer D, Agostini HT, Junker B, Pielen A. Switch of anti-VEGF agents is an option for nonresponders in the treatment of AMD. Eye (Lond). 2014;28(5):538-545.

109. Aslankurt M, Aslan L, Aksoy A, Erden B, Cekic O. The results of switching between 2 anti-VEGF drugs, bevacizumab and ranibizumab, in the treatment of neovascular age-related macular degeneration. Eur J Ophthalmol. 2013;23(4):553-557.

110. Pinheiro-Costa J, Freitas-da-Costa P, Falcao MS, Brandao EM, Falcao-Reis F, Carneiro AM. Switch from intravitreal ranibizumab to bevacizumab for the treatment of neovascular age-related macular degeneration: clinical comparison. Ophthalmologica. 2014;232(3): $149-155$.

111. Kumar N, Marsiglia M, Mrejen S, et al. Visual and anatomical outcomes of intravitreal aflibercept in eyes with persistent subfoveal fluid despite previous treatments with ranibizumab in patients with neovascular age-related macular degeneration. Retina. 2013;33(8):1605-1612.

112. Fassnacht-Riederle H, Becker M, Graf N, Michels S. Effect of aflibercept in insufficient responders to prior anti-VEGF therapy in neovascular AMD. Graefes Arch Clin Exp Ophthalmol. 2014;252(11):1705-1709.

113. Singh RP, Srivastava S, Ehlers JP, Bedi R, Schachat AP, Kaiser PK. A single-arm, investigator-initiated study of the efficacy, safety and tolerability of intravitreal aflibercept injection in subjects with exudative age-related macular degeneration, previously treated with ranibizumab or bevacizumab: 6-month interim analysis. $\mathrm{Br} J$ Ophthalmol. 2014;98(suppl 1):i22-i27.
114. Ferrone PJ, Anwar F, Naysan J, et al. Early initial clinical experience with intravitreal aflibercept for wet age-related macular degeneration. Br J Ophthalmol. 2014;98(suppl 1):i17-i21.

115. Hall LB, Zebardast N, Huang JJ, Adelman RA. Aflibercept in the treatment of neovascular age-related macular degeneration in previously treated patients. J Ocul Pharmacol Ther. 2014;30(4):346-352.

116. Messenger WB, Campbell JP, Faridi A, et al. Injection frequency and anatomic outcomes 1 year following conversion to aflibercept in patients with neovascular age-related macular degeneration. Br J Ophthalmol. 2014;98(9):1205-1207.

117. Ho VY, Yeh S, Olsen TW, et al. Short-term outcomes of aflibercept for neovascular age-related macular degeneration in eyes previously treated with other vascular endothelial growth factor inhibitors. Am J Ophthalmol. 2013;156(1):23-28.e22.

118. Heussen FM, Shao Q, Ouyang Y, Joussen AM, Muller B. Clinical outcomes after switching treatment from intravitreal ranibizumab to aflibercept in neovascular age-related macular degeneration. Graefes Arch Clin Exp Ophthalmol. 2014;252(6):909-915.

119. Cho H, Shah CP, Weber M, Heier JS. Aflibercept for exudative AMD with persistent fluid on ranibizumab and/or bevacizumab. $B r J$ Ophthalmol. 2013;97(8):1032-1035.

120. Gaudreault J, Fei D, Beyer JC, et al. Pharmacokinetics and retinal distribution of ranibizumab, a humanized antibody fragment directed against VEGF-A, following intravitreal administration in rabbits. Retina. 2007;27(9):1260-1266.

121. Abdullah SE, Perez-Soler R. Mechanisms of resistance to vascular endothelial growth factor blockade. Cancer. 2012;118(14): 3455-3467.

122. Inai $\mathrm{T}$, Mancuso $\mathrm{M}$, Hashizume $\mathrm{H}$, et al. Inhibition of vascular endothelial growth factor (VEGF) signaling in cancer causes loss of endothelial fenestrations, regression of tumor vessels, and appearance of basement membrane ghosts. Am J Pathol. 2004;165(1):35-52.

123. Huang J, Soffer SZ, Kim ES, et al. Vascular remodeling marks tumors that recur during chronic suppression of angiogenesis. Mol Cancer Res. 2004;2(1):36-42.

124. Wu E, Palmer N, Tian Z, et al. Comprehensive dissection of PDGFPDGFR signaling pathways in PDGFR genetically defined cells. PLoS One. 2008;3(11):e3794.

125. Abramsson A, Lindblom P, Betsholtz C. Endothelial and nonendothelial sources of PDGF-B regulate pericyte recruitment and influence vascular pattern formation in tumors. $J$ Clin Invest. 2003;112(8):1142-1151.

126. Rusnati M, Presta M. Fibroblast growth factors/fibroblast growth factor receptors as targets for the development of anti-angiogenesis strategies. Curr Pharm Des. 2007;13(20):2025-2044.

127. Presta M, Dell'Era P, Mitola S, Moroni E, Ronca R, Rusnati M. Fibroblast growth factor/fibroblast growth factor receptor system in angiogenesis. Cytokine Growth Factor Rev. 2005;16(2):159-178.

128. Kaiser PK. Emerging therapies for neovascular age-related macular degeneration: drugs in the pipeline. Ophthalmology. 2013;120(5 suppl): S11-S15.

129. Rofagha S, Bhisitkul RB, Boyer DS, Sadda SR, Zhang K; SEVEN-UP Study Group. Seven-year outcomes in ranibizumab-treated patients in ANCHOR, MARINA, and HORIZON: a multicenter cohort study (SEVEN-UP). Ophthalmology. 2013;120(11):2292-2299.

\section{Publish your work in this journal}

Drug Design, Development and Therapy is an international, peerreviewed open-access journal that spans the spectrum of drug design and development through to clinical applications. Clinical outcomes, patient safety, and programs for the development and effective, safe, and sustained use of medicines are a feature of the journal, which

\section{Dovepress}

has also been accepted for indexing on PubMed Central. The manuscript management system is completely online and includes a very quick and fair peer-review system, which is all easy to use. Visit http://www.dovepress.com/testimonials.php to read real quotes from published authors. 